\title{
Prediction of outcome after diagnosis of metachronous contralateral breast cancer
}

\author{
Sara Alkner ${ }^{1,4}$, Pär-Ola Bendahl ${ }^{1}$, Mårten Fernö ${ }^{1}$, Jonas Manjer ${ }^{2,5}$ and Lisa Rydén ${ }^{3,6^{*}}$
}

\begin{abstract}
Background: Although 2-20\% of breast cancer patients develop a contralateral breast cancer (CBC), prognosis after CBC is still debated. Using a unique patient cohort, we have investigated whether time interval to second breast cancer (BC2) and mode of detection are associated to prognosis.

Methods: Information on patient-, tumour-, treatment-characteristics, and outcome was abstracted from patients' individual charts for all patients diagnosed with metachronous CBC in the Southern Healthcare Region of Sweden from 1977-2007. Distant disease-free survival (DDFS) and risk of distant metastases were primary endpoints.

Results: The cohort included 723 patients with metachronous contralateral breast cancer as primary breast cancer event. Patients with less than three years to BC2 had a significantly impaired DDFS ( $p=0.01)$, and in sub-group analysis, this effect was seen primarily in patients aged $<50$. By logistic regression analysis, patients diagnosed with BC2 within routine follow-up examinations had a significantly lower risk of developing metastases compared to those who were symptomatic at diagnosis $(p<0.0001)$. Chemotherapy given after breast BC1 was a negative prognostic factor for DDFS, whereas endocrine treatment and radiotherapy given after BC2 improved DDFS.

Conclusions: In a large cohort of patients with CBC, we found the time interval to BC2 to be a strong prognostic factor for DDFS in young women and mode of detection to be related to risk of distant metastases. Future studies of tumour biology of BC2 in relation to prognostic factors found in the present study can hopefully provide biological explanations to these findings.
\end{abstract}

Keywords: metachronous breast cancer contralateral breast cancer, prognosis, detection, adjuvant therapy

\section{Background}

Within their lifetime, $2-20 \%$ of breast cancer patients develop a new tumour in their contralateral breast [1-3]. These contralateral breast cancers $(\mathrm{CBC})$ are called synchronous if the second tumour (BC2) develops within a short time interval from the first tumour (BC1), and metachronous if the time interval between tumours is longer. In line with several previous studies, we define metachronous tumours as CBC diagnosed at least three months after BC1 [3-5]. However, a clear cut-off time is not defined in the literature. $\mathrm{CBC}$ is today treated as a new primary tumour (two individual tumours), but the biological relationship between $\mathrm{BC} 1$ and $\mathrm{BC}$, and the impact of a second primary tumour on prognosis is debated [4,6-18]. Previous studies indicate that

\footnotetext{
* Correspondence: lisa.ryden@med.lu.se

${ }^{3}$ Department of Surgery, Clinical Sciences, Lund, Lund University, Sweden

Full list of author information is available at the end of the article
}

prognosis after $\mathrm{CBC}$ could be associated with age, time interval between $\mathrm{BC} 1$ and $\mathrm{BC} 2$, mode of detection of $\mathrm{BC} 2$, and adjuvant treatment for $\mathrm{BC} 1[4,15-17,19]$. However, despite women with a history of breast cancer have a high lifetime risk of developing $\mathrm{CBC}$, the annual risk remains at a relative low level of $0.5-1 \%$. A long followup time is hence needed in order to obtain a large cohort of patients with $\mathrm{CBC}$.

For this study data was abstracted from individual charts for all patients diagnosed with metachronous CBC in the Southern Healthcare Region of Sweden (a region with 1.7 million inhabitants) from 1977 to 2007. This gave us a unique cohort, including more than 700 patients from multiple medical centres, providing information on patient and tumour characteristics, treatment, and outcome. The aims of this study were to examine prognosis after $\mathrm{CBC}$ in relation to time interval between
C Biomed Central 
$\mathrm{BC} 1$ and $\mathrm{BC} 2$, mode of detection of $\mathrm{BC} 2$, and treatment for $\mathrm{BC} 1$.

\section{Methods Study Cohort}

Inclusion criteria were patients within the Southern Swedish Healthcare Region with two breast cancers reported in the Swedish Cancer Register, with the second tumour diagnosed between 1977 and 2007. The Swedish Cancer Register is a nationwide database including the International Classification of Diseases code and date of diagnosis. The study cohort includes patients from 14 hospitals (Lund, Malmö, Helsingborg, Ängelholm, Landskrona, Ystad, Trelleborg, Hässleholm, Kristianstad, Växjö, Ljungby, Halmstad, Karlshamn, and Karlskrona) within the Southern Healthcare Region of Sweden. All hospitals were active members of the South Sweden Breast Cancer Group, established in 1977, and used the common guidelines for diagnosis, treatment, and follow-up. The follow-up program included annual physical examination and mammogram. From 1977 to 1995 the recommended follow-up period was ten years, which was down-scaled to five years from 1995 to 2002, and three years from 2002 onwards. The regular surveillance program was additionally followed by admittance to the screening program for mammographic examinations every 24 months.

The cohort retrieved from the register initially included 1970 patients. The flow-chart of the study is given in Figure 1. After exclusion according to predefined exclusion criteria, our cohort included 723 patients with metachronous contralateral breast cancer as primary event. For patients with multiple exclusion criteria, the first criterion mentioned in the chart is listed in Figure 1.

\section{Data abstraction of clinical information}

From September 2007 to November 2009, data was abstracted from individual charts (clinical notes, pathology-, and X-ray-records) in a systematised manner, using a predefined protocol. The protocol was designed at the Department of Medical Epidemiology and Biostatistics, KI Stockholm, for collecting data from patients with CBC. Individual charts at the Departments of surgery as well as the Departments of oncology (Lund and Malmö) were retrieved, in order to optimise data abstraction and minimise patients lost to follow-up. The protocol used included data on mode of detection as well as surgical and oncological treatment for $\mathrm{BC} 1$ and $\mathrm{BC} 2$. Patients diagnosed within a follow-up programme were considered asymptomatic at time of diagnosis, whereas patients who first noted symptoms themselves and thereafter contacted their physicians were considered symptomatic. Patients were considered to have received endocrine treatment only if they had continued treatment for at least three months. Due to the long follow-up period of the study cohort, oestrogen receptor status for both tumours were available for less than half of the patients, and histological grade for less than one third. Additionally, scoring methods to determine histological grade differed during the study follow-up period and between various pathology departments. Neither oestrogen receptor status, nor histological grade, was hence used for further statistical analysis in the present study.

Previous studies use different time intervals to $\mathrm{BC} 2$ to separate early from late metachronous CBC. A time interval of three years has been used for a multitude of previous studies $[13,15,16]$, and this interval was hence selected for all analysis presented in this report. Unless otherwise stated, age refers to the age at diagnosis of $\mathrm{BC} 1$, in line with earlier studies $[4,14,16,20]$. To examine the effect of calendar period at diagnosis of $\mathrm{CBC}$ on prognosis, we divided the material into three calendar periods, 1977 to 1986, 1987 to 1996, and 1997 to 2007.

\section{Ethical Considerations}

This project has been approved by the ethical committee of Lund University (LU 240-01). All information and data was handled confidentially, and evaluation of information linked to patients was carried out in accordance with the Swedish Personal Data Act (Personuppgiftslagen in Swedish).

\section{End-points and follow-up}

Distant disease-free survival (DDFS) was chosen as primary end-point of the study. DDFS includes development of distant metastases (visceral, skeletal, brain, or cutaneous metastases) as a primary event. Loco-regional recurrences were not regarded as events in analysis of DDFS, and event-free survival was measured from diagnosis of CBC. Survival from BC1 was not considered since that would automatically prolong the follow-up until event for patients with a longer time interval between tumours, and hence bias the results. If no prior event was recorded, DDFS was calculated to the last follow-up date in the patient's individual chart. For patients who developed a malignancy other than breast cancer after diagnosis of $\mathrm{CBC}$, the diagnosis date of this malignancy was considered to be the last follow-up date.

\section{Statistical Analysis}

For statistical calculations, the software package Stata 10.1 (StataCorp. 2008. College Station, TX, USA) was used. Kaplan-Meier plots were used to describe DDFS and the log-rank test was used to evaluate hypotheses of equal survival. Kaplan-Meier curves were curtailed when less than five individuals remained at risk. Cox regression was used 




Figure 1 Flow-chart of inclusion vs. exclusion in the study cohort.

to estimate hazard ratios (HR), and assumptions of proportional hazards were checked graphically. Retrospective studies of prognosis in relation to mode of detection could be affected by lead-time bias (earlier detection leads to a longer follow-up until event, even if disease progression is the same). To avoid this we looked at the risk of distant metastasis as a primary event instead of DDFS in relation to mode of detection. Logistic regression was therefore used to compare risk of metastasis in different sub-groups. Multivariate analyses presented do not include patients 
with missing values for any of the variables included. However, the analyses were repeated for all patients by treating the missing category for discrete variables as a separate category and by imputing the sample mean over all patients for continuous variables. To assess whether the effect of time interval to $\mathrm{BC} 2$ or mode of detection differed with age, a Cox model was used with a term for interaction between each of these factors and age. Age was categorised as over or equal to $v s$. under age 50 at diagnosis of $\mathrm{BC} 1$. All p-values correspond to two-sided tests and values less than 0.05 were considered significant.

\section{Results}

\section{Clinical information}

Patient, tumour and treatment characteristics are described in Table 1. The median duration of follow-up after BC2 was 5.6 years (IQR 2.0-9.1) for all patients without an event. Median duration of follow-up for patients with a time interval to $\mathrm{BC} 2$ less than three years was 7.0 years, and for those with a time interval to $\mathrm{BC} 2$ of three years or more, 5.4 years. The median time to development of metastasis after $\mathrm{BC} 2$ was 2.2 years.

For patients operated for BC1, 524 patients (73\%) received surgery with a modified radical mastectomy and 193 (27\%) breast conserving surgery. The corresponding numbers for $\mathrm{BC} 2$ were 498 (71\%) with modified radical mastectomy and 206 (29\%) breast conserving surgery. Endocrine treatment included tamoxifen, aromatase inhibitors, and/or ooforectomy. For over $80 \%$ of patients the endocrine treatment given was tamoxifen.

Mode of detection of $\mathrm{BC} 2$ was known for 692 patients. Of these, 250 patients first noted the symptoms themselves, 97 patients were diagnosed by clinical examination, 257 patients by clinical mammography during follow-up, and 70 patients by screening mammography after re-admittance to the screening programme. Eighteen patients were diagnosed by other means (such as prophylactic mastectomy, or examination for other symptoms). These patients, along with 31 patients with missing data, were excluded from further analysis in regard to mode of detection. Patients who first noted symptoms themselves were considered symptomatic, while those diagnosed with clinical examination or mammography were considered asymptomatic at diagnosis.

\section{Time interval between first and second breast cancer in relation to prognosis}

The time interval between $\mathrm{BC} 1$ and $\mathrm{BC} 2$ was $0.30-36$ years, with a median of 6.7 years. A time interval of less than five years was most common (42\%) between diagnosis of $\mathrm{BC} 1$ and $\mathrm{BC} 2$, with a decline in the percentage of patients diagnosed with $\mathrm{BC} 2$ the longer the time interval to BC2 (5-9 years $24 \%, 10-14$ years $16 \%, 15-19$ years $9 \%, 20-24$ years $5 \%$, 25-29 years $2 \%$, 30-34 years $1 \%$, and $\geq 35$ years $0 \%$ ). Patient and tumour characteristics in relation to time interval to $\mathrm{BC} 2$ are described in Table 2.

When exploring the time interval to $\mathrm{BC} 2$ as a continuous variable, we found a significantly improved DDFS per year the longer the time interval to $\mathrm{BC} 2(\mathrm{HR}=0.97$, $\mathrm{p}=0.002$, 95\% CI 0.94-0.99). This result remained statistically significant in multivariate analysis adjusted for age, calendar period, mode of detection of $\mathrm{BC} 2$, tumour size, lymph node status, and treatment for $\mathrm{BC} 1$ and $\mathrm{BC} 2$ $(\mathrm{HR}=0.94, \mathrm{p}<0.001,95 \% \mathrm{CI} 0.91-0.97)$. When dividing the time interval $\geq 3$ years to $\mathrm{BC} 2$ into two separate categories, 3-9 years and $\geq 10$ years, we found that DDFS seems to improve continuously with increasing time interval to $\mathrm{BC} 2$. Compared to patients with a time interval to $\mathrm{BC} 2$ of $\geq 10$ years (the selected reference group), patients with a time interval of 3-10 years had a HR of 1.3 ( $\mathrm{p}=0.1,95 \%$ CI 0.95-1.9), whereas patients with a time interval of less than three years had a HR of 1.7 (p $=0.003,95 \%$ CI 1.2-2.4).

Patients with a time interval to $\mathrm{BC} 2$ of less than three years had a significantly impaired DDFS compared to patients with a time interval of more than three years (Figure 2, Table 3). Statistical significance remained in multivariate analysis adjusted for age, calendar period, mode of detection of $\mathrm{BC} 2$, tumour size, lymph node status, and treatment for BC1 and BC2 (Table 3).

Subgroup analysis showed that women younger than 50 years when diagnosed with $\mathrm{BC} 1$ had a significantly worse DDFS if the time interval to $\mathrm{BC} 2$ was less than three years (Figure 3, Table 3). This result remained statistically significant in multivariate analysis (Table 3). However, for women of 50 years or older, no significant difference was seen in regard to time interval to BC2 neither in univariate- nor multivariate analysis (Figure 3, Table 3). When using a Cox model with main effects for age and time interval to $\mathrm{BC} 2$, and a term for the interaction between these variables, the interaction was statistically significant $(\mathrm{HR}=0.53, \mathrm{p}=0.03,95 \% \mathrm{CI}$ 0.30-0.94). However, when the data was adjusted for calendar period, mode of detection of $\mathrm{BC} 2$, tumour size, lymph node status, and treatment for $\mathrm{BC} 1$ and $\mathrm{BC} 2$, no statistical significance remained. Multivariate analyses were repeated to include patients with missing values, indicating similar results as above.

Menopausal status at diagnosis of both $\mathrm{BC} 1$ and $\mathrm{BC} 2$ was known for 611 patients (85\%). Repeating analyses according to menopausal status, results for premenopausal patients and patients who switched menopausal status between tumours were similar to those observed for patients $<50$ years at $\mathrm{BC} 1$, while results for postmenopausal patients were similar to those observed for 
Table 1 Patient, tumour, and treatment characteristics in relation to development of metastasis after BC2

\begin{tabular}{|c|c|c|c|c|}
\hline \multirow[b]{3}{*}{ No $=723$} & \multicolumn{2}{|c|}{ First breast cancer, No (\%) } & \multicolumn{2}{|c|}{ Second breast cancer, No (\%) } \\
\hline & Metastasis & No metastasis & Metastasis & No metastasis \\
\hline & $\mathrm{No}=210$ & No $=513$ & No $=210$ & No $=513$ \\
\hline \multicolumn{5}{|l|}{ Diagnosis } \\
\hline$<1977$ & $37(18)$ & $97(19)$ & 0 & 0 \\
\hline 1977-1986 & $66(31)$ & $161(31)$ & $53(25)$ & $95(19)$ \\
\hline 1987-1996 & $79(38)$ & $191(37)$ & $78(37)$ & $179(35)$ \\
\hline $1997-2007$ & $28(13)$ & $64(12)$ & $79(38)$ & $239(47)$ \\
\hline \multicolumn{5}{|l|}{ Age (years) } \\
\hline Median (range) & $52(27-85)$ & $60(30-90)$ & $60(32-92)$ & $70(32-98)$ \\
\hline$<50$ & $94(45)$ & $123(24)$ & $50(24)$ & $34(7)$ \\
\hline$\geq 50$ & $116(55)$ & $390(76)$ & $160(76)$ & $479(93)$ \\
\hline \multicolumn{5}{|l|}{ Menopausal status } \\
\hline Premenopausal & $100(51)$ & $132(28)$ & $29(16)$ & $32(7)$ \\
\hline Postmenopausal & $96(49)$ & $336(72)$ & $148(84)$ & $440(93)$ \\
\hline Missing & 14 & 45 & 33 & 41 \\
\hline \multicolumn{5}{|l|}{ Node status } \\
\hline No & $105(53)$ & $330(72)$ & $97(50)$ & $292(73)$ \\
\hline $\mathrm{N}+$ & $92(47)$ & $130(28)$ & $96(50)$ & $106(27)$ \\
\hline Missing & 13 & 53 & 17 & 115 \\
\hline \multicolumn{5}{|l|}{ Size $(\mathrm{mm})$} \\
\hline Median (range) & $20(1-90)$ & $15(1-100)$ & $18(1-110)$ & $14(1-90)$ \\
\hline Missing & 28 & 50 & 17 & 20 \\
\hline \multicolumn{5}{|l|}{ Surgery } \\
\hline Modified radical mastectomy & $162(78)$ & $362(71)$ & $158(75)$ & $340(66)$ \\
\hline Partial mastectomy & $44(21)$ & $149(29)$ & $45(21)$ & $161(31)$ \\
\hline No Surgery & $1(0.5)$ & 0 & $6(3)$ & $12(2)$ \\
\hline Missing & 3 & 2 & 1 & 0 \\
\hline \multicolumn{5}{|l|}{ Radiotherapy } \\
\hline No & $56(27)$ & $213(42)$ & $122(58)$ & $360(70)$ \\
\hline Yes & $153(73)$ & $293(58)$ & $87(42)$ & $152(30)$ \\
\hline Missing & 1 & 7 & 1 & 1 \\
\hline \multicolumn{5}{|l|}{ Chemotherapy } \\
\hline No & $172(82)$ & $473(94)$ & $178(85)$ & $491(96)$ \\
\hline Yes & $37(18)$ & $32(6)$ & $31(15)$ & $21(4)$ \\
\hline Missing & 1 & 8 & 1 & 1 \\
\hline Endocrine treatment $\mathrm{No}$ & $158(76)$ & $391(77)$ & $132(64)$ & $296(58)$ \\
\hline Yes & $51(24)$ & $114(23)$ & $74(36)$ & $215(42)$ \\
\hline Missing & 1 & 8 & 4 & 2 \\
\hline
\end{tabular}

Abbreviations: No number, N+ lymph node metastases, N0 no lymph node metastases, node status lymph node status.

patients $\geq 50$ years (data not shown). Out of the 198 patients who were $<50$ years old at $\mathrm{BC} 1$, only $9(5 \%)$ were postmenopausal, whereas for the 466 patients $\geq 50$ years of age at BC1, only 43 (9\%) were premenopausal. An age-limit of 50 years hence seems to effectively separate pre- and postmenopausal women.

Mode of detection in relation to prognosis

For 424 (63\%) of the patients, CBC was diagnosed within a follow-up programme, whereas 250 patients
(37\%) first noted symptoms themselves and thereafter contacted their physician. The median duration of follow-up after BC2 for patients without an event was 5.4 years for symptomatic patients, and 5.7 years for asymptomatic patients. Patient and tumour characteristics are described in Table 2.

Patients with symptoms at diagnosis were younger and had a longer time interval between tumours. Additionally their contralateral tumours were larger, and more often combined with the occurrence of lymph node metastases 
Table 2 Patient, tumour, and treatment characteristics in relation to time interval to and mode of detection of the second breast cancer

\begin{tabular}{|c|c|c|c|c|c|c|c|c|}
\hline & \multicolumn{4}{|c|}{ Time interval to second breast cancer } & \multicolumn{4}{|c|}{ Mode of detection of second breast cancer ${ }^{a}$} \\
\hline & \multicolumn{2}{|c|}{$\begin{array}{c}\text { First breast cancer, No } \\
(\%)\end{array}$} & \multicolumn{2}{|c|}{$\begin{array}{c}\text { Second breast cancer, } \\
\text { No (\%) }\end{array}$} & \multicolumn{2}{|c|}{ First breast cancer, No (\%) } & \multicolumn{2}{|c|}{$\begin{array}{c}\text { Second breast cancer, No } \\
\text { (\%) }\end{array}$} \\
\hline & $<3$ years & $\geq 3$ years & $<3$ years & $\geq 3$ years & Symptomatic & Asymptomatic & Symptomatic & Asymptomatic \\
\hline & No $=200$ & No $=523$ & No $=200$ & No $=523$ & No $=250$ & No $=424$ & No $=250$ & No $=424$ \\
\hline \multicolumn{9}{|c|}{ Diagnosis of $\mathrm{BC} 2$} \\
\hline$<1977$ & $1(1)$ & $133(25)$ & 0 & 0 & $70(28)$ & $55(13)$ & 0 & 0 \\
\hline 1977-1986 & $59(30)$ & $168(32)$ & $48(24)$ & $100(19)$ & $77(31)$ & $132(31)$ & $57(23)$ & $79(19)$ \\
\hline 1987-1996 & $84(42)$ & $186(36)$ & $80(40)$ & $177(34)$ & $84(34)$ & $174(41)$ & $89(36)$ & $150(35)$ \\
\hline 1997-2007 & $56(28)$ & $36(7)$ & $72(36)$ & $246(47)$ & $19(8)$ & $63(15)$ & $104(42)$ & $195(46)$ \\
\hline \multicolumn{9}{|l|}{ Age } \\
\hline Median (range) & $59(39-89)$ & $57(27-90)$ & $60(32-91)$ & $69(36-98)$ & $54(27-89)$ & $59(30-87)$ & 66 (35-97) & 68 (32-93) \\
\hline$<50$ years & $55(28)$ & $162(31)$ & $48(24)$ & $36(7)$ & $96(38)$ & $110(26)$ & $45(18)$ & $34(8)$ \\
\hline$\geq 50$ years & $145(73)$ & $361(69)$ & $152(76)$ & $487(93)$ & $154(62)$ & $314(74)$ & $205(82)$ & $390(92)$ \\
\hline \multicolumn{9}{|l|}{ Node status } \\
\hline NO & $111(60)$ & $324(69)$ & $108(65)$ & $281(66)$ & 161 (72) & $253(65)$ & $117(56)$ & $251(71)$ \\
\hline $\mathrm{N}+$ & $75(40)$ & $147(31)$ & $59(35)$ & $143(34)$ & $62(28)$ & $138(35)$ & $91(44)$ & $104(29)$ \\
\hline Missing & 14 & 52 & 33 & 99 & 27 & 33 & 42 & 69 \\
\hline \multicolumn{9}{|l|}{ Size $(\mathrm{mm})$} \\
\hline Median (range) & $17(1-100)$ & $17(1-70)$ & $14(1-110)$ & $15(1-85)$ & $18(1-90)$ & $17(1-100)$ & $19(1-110)$ & $13(1-90)$ \\
\hline Missing & 6 & 72 & 10 & 27 & 38 & 32 & 12 & 19 \\
\hline \multicolumn{9}{|l|}{ Radiotherapy } \\
\hline No & $89(45)$ & $180(35)$ & $121(61)$ & $361(69)$ & $96(39)$ & $153(36)$ & $158(63)$ & $283(67)$ \\
\hline Yes & $111(56)$ & $335(65)$ & $79(40)$ & $160(31)$ & $152(61)$ & $268(64)$ & $91(37)$ & $141(33)$ \\
\hline Missing & 0 & 8 & 0 & 2 & 2 & 3 & 1 & 0 \\
\hline \multicolumn{9}{|l|}{ Chemotherapy } \\
\hline No & $167(84)$ & $478(93)$ & 177 (89) & $492(94)$ & $227(92)$ & $376(89)$ & $220(88)$ & $402(95)$ \\
\hline Yes & $33(17)$ & $36(7)$ & $23(12)$ & $29(6)$ & $20(8)$ & $45(11)$ & $29(12)$ & $22(5)$ \\
\hline Missing & 0 & 9 & 0 & 2 & 3 & 3 & 1 & 0 \\
\hline \multicolumn{9}{|c|}{ Endocrine treatment } \\
\hline No & $148(74)$ & $401(78)$ & $124(63)$ & $304(59)$ & $202(82)$ & $313(74)$ & $146(59)$ & $249(59)$ \\
\hline Yes & $52(26)$ & $113(22)$ & $74(37)$ & $215(41)$ & $45(18)$ & $108(26)$ & $102(41)$ & $172(41)$ \\
\hline Missing & 0 & 9 & 2 & 4 & 3 & 3 & 2 & 3 \\
\hline \multicolumn{9}{|c|}{ Mode of detection of $\mathrm{BC2}$} \\
\hline Symptomatic & & & $57(31)$ & $193(40)$ & & & & \\
\hline Asymptomatic & & & $129(69)$ & $295(60)$ & & & & \\
\hline Missing & & & 14 & 35 & & & & \\
\hline \multicolumn{9}{|c|}{ Time interval to $\mathrm{BC2}$} \\
\hline Median (range) & & & & & & & $9.1(0.37-36)$ & $5.8(0.30-34)$ \\
\hline$<3$ years & & & & & & & $57(23)$ & $129(30)$ \\
\hline$\geq 3$ years & & & & & & & $193(77)$ & $295(70)$ \\
\hline
\end{tabular}

a 49 patients were excluded from analyses regarding mode of detection due to missing data or diagnosis by other means than mammography, clinical examination or symptoms noted by the patient.

Abbreviations: N+ lymph node metastases, N0 no lymph node metastases, No number, node status lymph node status.

(Table 2). Using logistic regression, a significantly higher risk of developing metastases was seen in patients who were symptomatic at diagnosis (Table 4). The statistical significance remained when adjusting for age, calendar period, tumour size, node status, and treatment for both tumours. This suggests that finding $\mathrm{BC} 2$ at an earlier stage is not the only factor improving prognosis in patients asymptomatic at diagnosis. Multivariate analyses were repeated to include patients with missing values. All analyses yielded similar results as described above.

Mode of detection remained a significant risk factor for development of distant metastases when the time 


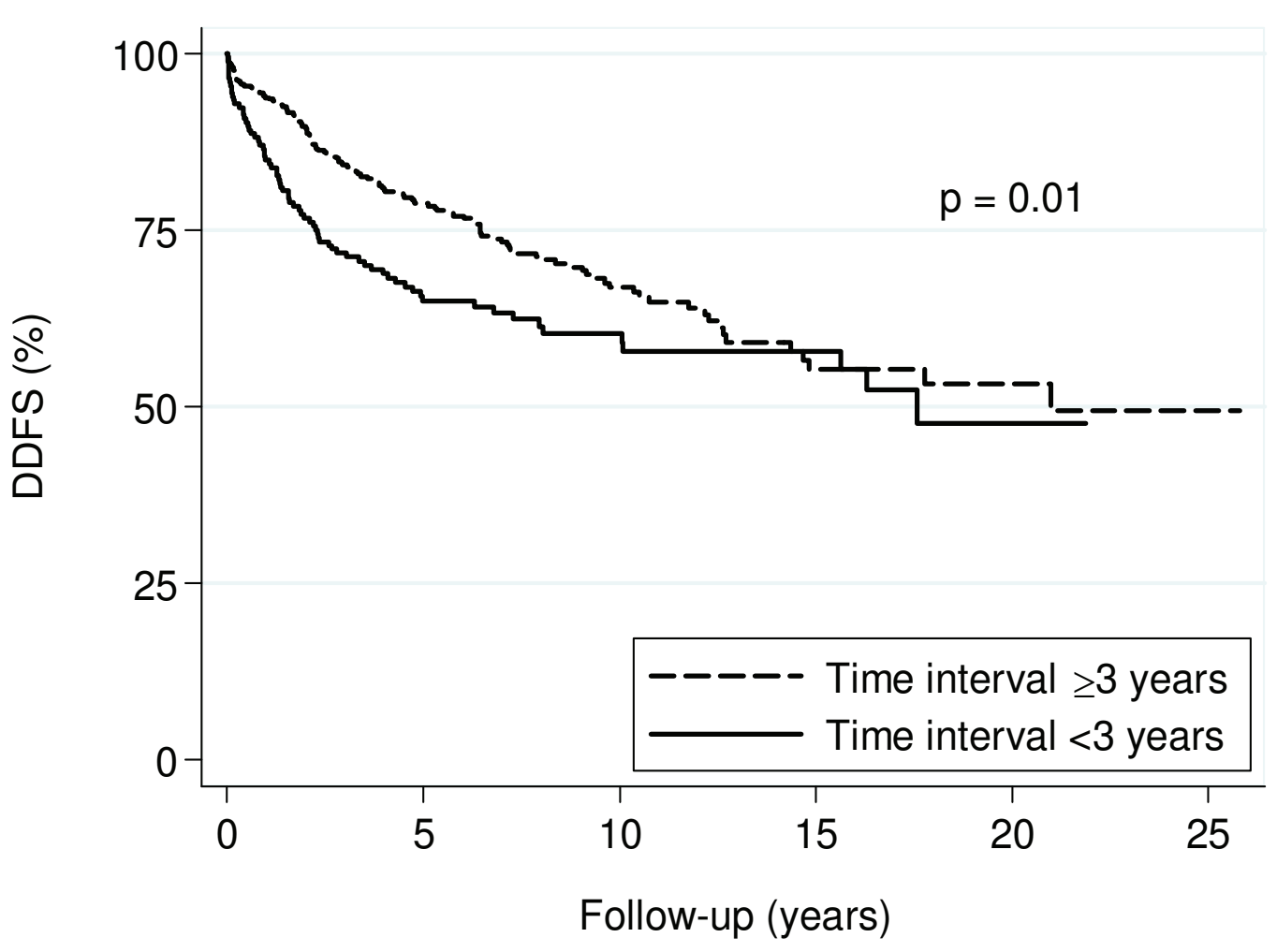

Numbers at risk

Time interval $\geq 3$ years 523

$259 \quad 107$

41

18

7

Time interval $<3$ years 200

96

48

25

9

0

Figure 2 Distant disease-free survival in relation to time interval to $\mathbf{B C 2}$. Abbreviations: BC2 the second breast cancer, DDFS distant disease-free survival, Interval time interval to $B C 2$.

Table 3 Cox-regression analysis for distant metastasis in relation to time interval to the second breast cancer

\begin{tabular}{|c|c|c|c|c|c|c|c|}
\hline Age at $\mathrm{BC} 1$ & $\begin{array}{c}\text { Time interval to } \\
\mathrm{BC} 2\end{array}$ & $\begin{array}{c}\text { Cases } \\
\text { No }\end{array}$ & $\begin{array}{c}\text { Metastasis } \\
\text { No }(\%)\end{array}$ & $\begin{array}{c}\text { Metastasis/100.000 } \\
\text { person-years }\end{array}$ & $\begin{array}{c}\mathrm{HR} \\
(95 \% \mathrm{Cl}) \\
\end{array}$ & $\begin{array}{c}\mathrm{HR}^{*} \\
(95 \% \mathrm{Cl})\end{array}$ & $\begin{array}{c}\mathrm{HR}^{* *} \\
(95 \% \mathrm{Cl})\end{array}$ \\
\hline All & $<3$ years & 200 & $74(37)$ & 5800 & $1.4(1.1-1.9)$ & $1.6(1.1-2.2)$ & $1.6(1.1-2.3)$ \\
\hline \multirow[t]{2}{*}{ No $=723$} & $\geq 3$ years & 523 & $136(26)$ & 4100 & 1.0 & 1.0 & 1.0 \\
\hline & & & & & $p=0.01$ & $p=0.009$ & $p=0.01$ \\
\hline$<50$ years & $<3$ years & 55 & $34(62)$ & 11000 & $2.2(1.4-3.4)$ & $2.0(1.2-3.4)$ & $2.2(1.2-3.8)$ \\
\hline \multirow[t]{2}{*}{$\mathrm{No}=217$} & $\geq 3$ years & 162 & $60(37)$ & 4900 & 1.0 & 1.0 & 1.0 \\
\hline & & & & & $p<0.0001$ & $p=0.01$ & $p=0.006$ \\
\hline$\geq 50$ years & $<3$ years & 145 & $40(28)$ & 4100 & $1.2(0.78-1.7)$ & $1.5(0.92-2.3)$ & $1.3(0.77-2.2)$ \\
\hline \multirow[t]{2}{*}{$\mathrm{No}=506$} & $\geq 3$ years & 361 & $76(21)$ & 3700 & 1.0 & 1.0 & 1.0 \\
\hline & & & & & $p=0.5$ & $p=0.1$ & $p=0.3$ \\
\hline
\end{tabular}

* Adjusted for calendar period (1977-1986, 1987-1996, 1997-2007), age (under vs. over 50 years at diagnosis of BC1), mode of detection of BC2 (symptomatic vs. asymptomatic), size (mm) of BC1 and BC2, and node status (N0 vs. N+) for BC1 and BC2. Multivariate analyses in subgroups divided by age are not adjusted for age again. No $=471,158$ patients $<50$ years and $313 \geq 50$ years.

** Adjusted for factors listed under * and in addition: treatment for BC1 and BC2 (radiotherapy, chemotherapy, endocrine treatment, yes vs. no for each of the variables). Multivariate analyses in subgroups divided by age are not adjusted for age again. No $=468,157$ patients $<50$ years and $311 \geq 50$ years.

Abbreviations: $\mathrm{BC} 1$ first breast cancer, $\mathrm{BC} 2$ second breast cancer, $\mathrm{Cl}$ confidence interval, HR hazard ratio, N+ lymph node metastases, N0 no lymph node metastases, No number, node status lymph node status. 


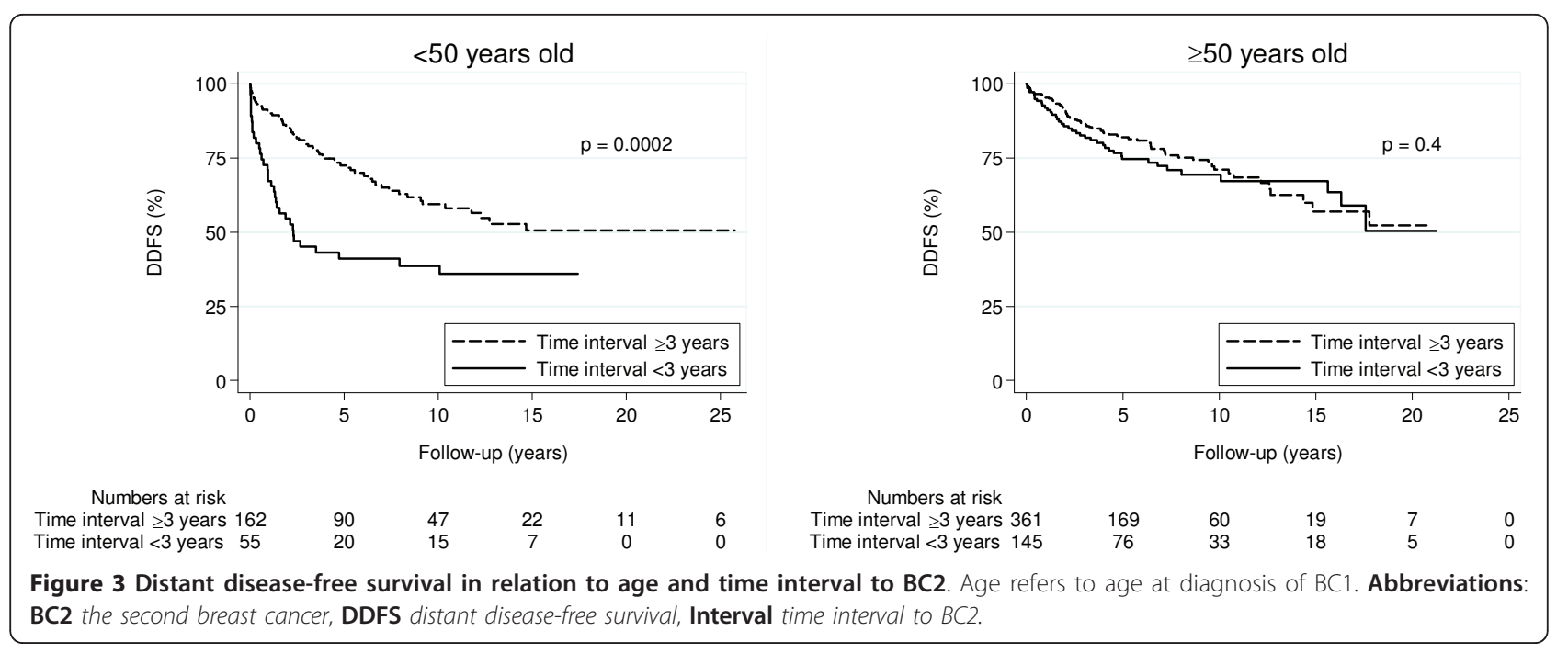

interval $\geq 3$ years to $\mathrm{BC} 2$ was divided into 2 separate categories; $3-9$ years and $\geq 10$ years, with a time interval of less than three years selected as reference group (3-9 years; $\mathrm{HR}=2.2, \mathrm{p}=0.00595 \% \mathrm{CI} 1.3-4.0 . \geq 10$ years; $\mathrm{HR}=3.0, \mathrm{p}=0.001,95 \% \mathrm{CI} 1.5-5.8$ ).

When comparing mode of detection for patients diagnosed by clinical examination with those diagnosed by mammography, patients diagnosed by mammography were younger, had smaller tumours, and more seldom lymph node metastases of BC2 (data not shown).
Additionally the risk of later metastasis was slightly, though not significantly, higher for patients diagnosed by clinical examination

\section{Association between adjuvant treatment and prognosis}

A multivariate Cox-regression analysis adjusted for time interval between tumours, calendar period of diagnosis, mode of detection of $\mathrm{BC} 2$, age at $\mathrm{BC} 1$, lymph node status, tumour size, and treatment for $\mathrm{BC} 1$ and $\mathrm{BC} 2$, showed chemotherapy given for $\mathrm{BC} 1$ to be an independent negative

Table 4 Logistic regression analysis for risk of metastasis in relation to mode of detection and time interval to the second breast cancer

\begin{tabular}{|c|c|c|c|c|c|c|}
\hline Patients groups & Mode of detection & $\begin{array}{c}\text { Cases } \\
\text { No }\end{array}$ & $\begin{array}{c}\text { Metastasis } \\
\text { No (\%) }\end{array}$ & $\begin{array}{c}\text { OR } \\
(95 \% \mathrm{Cl}) \\
\end{array}$ & $\begin{array}{c}\mathrm{OR}^{*} \\
(95 \% \mathrm{Cl})\end{array}$ & $\begin{array}{c}\text { OR }^{* *} \\
(95 \% \mathrm{Cl})\end{array}$ \\
\hline All & Symptomatic & 250 & $98(39)$ & $2.1(1.5-3.0)$ & $2.0(1.3-3.1)$ & $2.1(1.3-3.3)$ \\
\hline \multirow[t]{2}{*}{ No $=674$} & Asymptomatic & 424 & $99(23)$ & 1.0 & 1.0 & 1.0 \\
\hline & & & & $p<0.0001$ & $p=0.002$ & $p=0.002$ \\
\hline$<3$ years to $B C 2$ & Symptomatic & 57 & $30(53)$ & $2.4(1.3-4.5)$ & $1.7(0.71-4.1)$ & $1.7(0.67-4.2)$ \\
\hline \multirow[t]{2}{*}{ No $=186$} & Asymptomatic & 129 & $41(32)$ & 1.0 & 1.0 & 1.0 \\
\hline & & & & $p=0.008$ & $p=0.2$ & $p=0.3$ \\
\hline$\geq 3$ years to $B C 2$ & Symptomatic & 193 & $68(35)$ & $2.2(1.5-3.4)$ & $2.2(1.3-3.8)$ & $2.3(1.3-4.0)$ \\
\hline \multirow[t]{2}{*}{ No $=488$} & Asymptomatic & 295 & $58(20)$ & 1.0 & 1.0 & 1.0 \\
\hline & & & & $p<0.0001$ & $p=0.003$ & $p=0.003$ \\
\hline$<50$ years at $\mathrm{BC} 1$ & Symptomatic & 96 & $53(55)$ & $2.2(1.3-3.9)$ & $1.5(0.68-3.3)$ & $1.4(0.62-3.4)$ \\
\hline \multirow[t]{2}{*}{ No $=206$} & Asymptomatic & 110 & $39(35)$ & 1.0 & 1.0 & 1.0 \\
\hline & & & & $p=0.005$ & $p=0.3$ & $p=0.4$ \\
\hline$\geq 50$ years at $\mathrm{BC} 1$ & Symptomatic & 154 & $45(29)$ & $1.7(1.1-2.7)$ & $2.2(1.2-3.9)$ & $2.3(1.3-4.1)$ \\
\hline \multirow[t]{2}{*}{ No $=468$} & Asymptomatic & 314 & $60(19)$ & 1.0 & 1.0 & 1.0 \\
\hline & & & & $p=0.01$ & $p=0.006$ & $p=0.006$ \\
\hline
\end{tabular}

* Adjusted for calendar period (1977-1986, 1987-1996, 1997-2007), age (under vs. over 50 years at diagnosis of BC1), size (mm) of BC1 and BC2, and node status $(\mathrm{N} 0$ vs. $\mathrm{N}+$ ) for $\mathrm{BC} 1$ and $\mathrm{BC} 2$. No $=471,138$ patients with $<3$ years to $\mathrm{BC} 2$, and 333 patients with $\geq 3$ years to $\mathrm{BC} 2,158$ patients $<50$ years and $313 \geq 50$ years. ** Adjusted for $\mathrm{HR}^{*}$ and in addition: treatment for $\mathrm{BC} 1$ and $\mathrm{BC2}$ (radiotherapy, chemotherapy, endocrine treatment, yes vs. no for each of the variables.). No = 468 , 137 patients with $<3$ years and 331 patients with $\geq 3$ years to $B C 2,157$ patients $<50$ years and $311 \geq 50$ years.

Abbreviations: $\mathrm{BC} 1$ first breast cancer, $\mathrm{BC} 2$ second breast cancer, $\mathrm{Cl}$ confidence interval, DDFS distant disease-free survival, $\mathrm{N}+$ lymph node metastases, N0 no lymph node metastases, No number, node status lymph node status, OR odds ratio 
prognostic factor for DDFS $(\mathrm{HR}=2.1, \mathrm{p}=0.008,95 \% \mathrm{CI}$ 1.2-3.6). Radiotherapy delivered after $\mathrm{BC} 1$ did not reach statistical significance as a prognostic factor for DDFS (HR $=1.5, \mathrm{p}=0.07,95 \% \mathrm{CI} 0.98-2.3)$, and endocrine adjuvant treatment given after BC1 was not linked to DDFS (HR = $1.2, \mathrm{p}=0.5$, 95\% CI 0.74-1.9). However, adjuvant radiotherapy $(\mathrm{HR}=0.6, \mathrm{p}=0.007,95 \%$ CI $0.41-0.87)$ and endocrine treatment $(\mathrm{HR}=0.5, \mathrm{p}=0.001,95 \% \mathrm{CI} 0.33-0.74)$ after $\mathrm{BC} 2$ were positive prognostic factors, whereas chemotherapy given after BC2 had no effect on DDFS ( $\mathrm{HR}=$ $0.88, \mathrm{p}=0.6,95 \%$ CI 0.50-1.5). Multivariate analyses were repeated to include patients with missing values with similar results as described above.

\section{Discussion}

Using a large population-based cohort, including patient, tumour, and treatment information, we have studied prognosis after $\mathrm{CBC}$ in relation to time interval to, and mode of detection of $\mathrm{BC} 2$. A short time interval to $\mathrm{BC} 2$ was proven to be a significant negative prognostic factor, supporting earlier studies [4,15-17]. However subgroup analysis indicates that this effect is seen only for younger women. Data additionally indicate that women diagnosed by routine follow-up examination, have a significantly lower risk of developing metastases at a later stage.

In line with our data, previous studies have found a short time interval to $\mathrm{BC} 2$ to be associated with an impaired prognosis [4,15-17]. This study includes extended individual data from a large population-based cohort and strongly validate that a short time interval to $\mathrm{BC} 2$ is a negative prognostic factor. Time interval to $\mathrm{BC} 2$ was analysed both as a continuous and as a dichotomised variable with a cut-point of three years, and yielded independent prognostic information by both methods. Furthermore, previous results have differed when comparing prognosis after synchronous, metachronous, and unilateral breast cancer [10]. However, there have been indications that synchronous breast cancer (defined as CBC diagnosed within 3-12 months after $\mathrm{BC} 1$ ) might result in a worsened prognosis compared to metachronous breast cancer $[10,11,18]$.

The underlying cause for the impaired prognosis observed for $\mathrm{CBC}$ diagnosed within a short time interval from $\mathrm{BC} 1$ is unclear. One potential explanation could be that these tumours more often represent a metastatic spread of BC1. Comparisons of genetic alternations in bilateral breast cancer have shown that although most CBCs represent a new primary tumour, contralateral spreading from $\mathrm{BC} 1$ does occur [6-9]. A short time interval to $\mathrm{BC} 2$ has also been found to correlate with increased genetic and morphological similarities between bilateral tumours [21,22]. This could suggest a higher prevalence of metastatic spread, but could also be a result of these tumours having developed in a similar biological environment. Imyanitov et al. found the highest correlation between tumours in women who developed both tumours while premenopausal [21]. If this correlation results from a higher percentage of contralateral metastatic spread in these patients, it could partially explain the different effects of time interval to $\mathrm{BC} 2$ observed for the different age categories in our study, where most patients (95\%) diagnosed when under 50 years of age were premenopausal. However, Imyanitov et al. observed the lowest correlation between bilateral tumours separated by menopause, making hormonal environment at the time of development another likely cause to similarities $v s$. differences observed [21].

Another potential explanation could be that CBC diagnosed during, or soon after, adjuvant treatment has developed resistance to treatment and a more aggressive phenotype. The incidence of $\mathrm{CBC}$ in Sweden has decreased since the early 1980s [4]. This observation is potentially resulting from an increased use of adjuvant treatment, reducing the risk of CBC [2,3,23-25]. However, during the same time period mortality increased for those women who did develop CBC [4], which could reflect a treatment-escape phenomenon once therapy has failed to prevent a second tumour. CBC developed after tamoxifen treatment is also ER-negative to a larger extent [2,26-28], indicating that treatment given for $\mathrm{BC} 1$ affect the biology of $\mathrm{BC} 2$. If younger patients have received more adjuvant treatment, this might hence be one explanation to why the time interval between tumours is of greater importance in younger patients. In the present cohort we found support for this theory in that $\mathrm{BC} 1$ in younger patients was more often treated with radiotherapy and chemotherapy, while older women received more endocrine therapy (data not shown).

In this study chemotherapy given for $\mathrm{BC} 1$ was an independent negative prognostic factor, though this was not seen if chemotherapy had been given for $\mathrm{BC} 2$. Adjuvant endocrine treatment after $\mathrm{BC} 1$, however, had no effect on prognosis after BC2. Radiotherapy and endocrine treatment were positive prognostic factors if given after $\mathrm{BC} 2$, but not if given after BC1. Similar results have been seen in a study by Hartman et al and this could be interpreted as an indication that a CBC diagnosed after prior chemotherapy is more aggressive [4]. However, choice of adjuvant therapy is strongly dependent on tumour stage and biology, and patients selected to receive chemotherapy are those with the worst predicted prognosis. The survival analysis is adjusted for several prognostic factors including tumour stage and all treatment given. There are however still other factors, affecting prognosis and choice of therapy (hormone receptor status, histological grade, etc.) which are not 
provided for all patients in the present study, including patients for several decades. Hence, although these results are interesting and in line with those found by Hartman et al [4], they need to be interpreted with caution and further studies are required. The effect on prognosis by adjuvant endocrine treatment for $\mathrm{BC} 1$ is not fully elucidated since the cohort was not stratified according to hormone receptor status. Future studies including biomarker analysis of $\mathrm{BC} 1$ and $\mathrm{BC} 2$ can hopefully shed some light on this issue and, more importantly, on the effect of adjuvant treatment after $\mathrm{BC} 1$ on tumour biology of BC2.

Although early detection of distant metastases does not affect survival or quality of life $[29,30]$, recent studies suggest that early detection of local recurrences or CBC does improve prognosis [19,31,32]. However, results are not unanimous [33-35]. Previous studies are retrospective, leading to problems with lead-time (earlier detection results in a longer follow-up until event, even if the disease progression is the same) and length-time bias (slower growing tumours will be more easily detected, since they are detectable over a longer time period). To avoid lead-time bias we have looked at the risk of metastasis, using logistic regression, instead of DDFS with regard to mode of detection. Length-time bias may still be a problem in our study, although previous studies have not shown this to be a major source of concern [32,36-38]. We found that significantly fewer patients diagnosed with $\mathrm{CBC}$ within follow-up examinations subsequently developed metastases, which is probably to a large extent due to the fact that the tumours were discovered at an earlier stage. However, mode of detection remained a significant prognostic factor even after adjusting for tumour size, node status, and treatment for both tumours. This finding is in line with data from unilateral breast cancer, where diagnosis by screening mammography has been shown to be an independent prognostic factor even after adjustment for disease stage [39-42].

Presuming that surveillance after breast cancer diagnosis is effective, how long should it continue? In Sweden, a follow-up time of ten years was advocated until the mid-1990s. Today, clinical surveillance is often reduced to five years or less, followed by mammographic surveillance every 24 months within a screening program. In this study we found mode of detection to be associated with risk of metastasis even when $\mathrm{BC} 2$ was diagnosed more than ten years after $\mathrm{BC} 1$, suggesting that a long follow-up time could be of value.

The present study was based on a unique cohort, including over 700 patients with $\mathrm{CBC}$, with information on patient and tumour characteristics, treatment, and outcome. Despite the large selection of patients and information included in this study, some potential sources of bias should be considered. For example, subgroup analysis will include fewer events. Inclusion in the cohort was based on data from the Swedish Cancer Register which is nationwide. However, some cases of CBC might still be missing or misclassified, and 150 charts were never found. Although data from the patients' individual charts is probably more reliable than register data, the quality of clinical notes and pathological records varied over time and between physicians. Due to the low annual incidence of contralateral breast cancer, a long period of follow-up was needed to receive a large cohort. Hence, standard surgical methods, routine histopathological analysis and adjuvant treatment have changed during the study period. The patients were included in the cohort based on diagnose date of the CBC. Hence, for women initially treated before 1977, there could be a selection of patients with a longer time interval to $\mathrm{BC} 2$. When adjusting our analyses for diagnose date of $\mathrm{BC} 1$ the multivariate analysis of time interval to BC2 including all patients and treatment was no longer significant. Otherwise significance in all other analysis remained constant.

\section{Conclusions}

Patients with $\mathrm{CBC}$ are currently treated according to the tumour biology of $\mathrm{BC} 1$ and $\mathrm{BC} 2$ individually, and it is controversial whether prognosis after $\mathrm{CBC}$ is worse than after unilateral breast cancer [4,10-18]. Our study was based on clinical data from individual patients and results indicate that the time interval to $\mathrm{BC} 2$, especially for patients younger than 50 years, is a strong prognostic factor. Additionally, mode of detection was proven to be closely related to the risk of developing metastases. By taking time interval to $\mathrm{BC} 2$ and mode of detection into account when diagnosing patients with $\mathrm{CBC}$, this study seems to have identified patients with a poor prognosis. Indeed, among patients diagnosed with symptomatic $\mathrm{CBC}$ within three years from $\mathrm{BC} 1$, more than $50 \%$ later developed metastases. Further translational studies of the tumour biology of $\mathrm{BC} 2$ in relation to time interval, adjuvant treatment after $\mathrm{BC} 1$ and mode of detection are needed to confirm and explain these results.

\section{Abbreviations}

$B C 1$ : First breast cancer; $B C 2$ : Second breast cancer; $C B C$ : Contralateral breast cancer; Cl: Confidence interval; DDFS: Distant disease-free survival; HR: Hazard ratio; $I Q R$ : interquartile range.

\section{Acknowledgements}

We are indebted to the South-Swedish Oncological Centre providing us with data from the Cancer Register, and to the skilled and helpful staff at the surgical and oncological clinics, and at the medical archives in Lund, Malmö, Helsingborg, Ängelholm, Landskrona, Ystad, Trelleborg, Kristianstad, Växjö, Ljungby, Halmstad, Karlshamn and Karlskrona. Without their help this study could never have been accomplished. We are also indebted to Per 
Hall and Kamila Czene, Karolinska Institutet, Stockholm for providing us with the protocol used.

This work was supported by funds from the Swedish Cancer Society (070475); the Swedish Research Council (K2006-73X-20136-01-3); Gunnar, Arvid, and Elisabeth Nilsson Foundation (F52/08); Mrs. Berta Kamprad Foundation (BKS13/08; the University Hospital of Lund Research Foundation (H803); the Swedish Society for Medical Research and Governmental Funding of Clinical Research within Nation Health Service (ALF/FUA10623); and Skåne County Council's Research and Development Foundation.

\section{Author details}

${ }^{1}$ Department of Oncology, Clinical Sciences, Lund, Lund University, Sweden. ${ }^{2}$ Department of Surgery, Clinical Sciences, Malmö, Lund University, Sweden. ${ }^{3}$ Department of Surgery, Clinical Sciences, Lund, Lund University, Sweden. ${ }^{4}$ Skåne Department of Oncology, Skåne University Hospital, Sweden. ${ }^{5}$ Department of Surgery, Malmö, Skåne University Hospital, Sweden. ${ }^{6}$ Department of Surgery, Lund, Skåne University Hospital, Sweden.

\section{Authors' contributions}

SA abstracted data from the individual charts, participated in database construction, performed statistical analysis and drafted the manuscript, POB was responsible for database construction and statistical analysis and participated in the manuscript draft, JM participated in the statistical analysis, interpretation of the data and manuscript draft. MF participated in the design of the study, interpretation of the data and manuscript draft. LR participated in the design of the study, was responsible for data abstraction, interpretation of the data and manuscript draft. All authors read and approved the final manuscript.

\section{Competing interests}

The authors declare that they have no competing interests.

Received: 6 September 2010 Accepted: 30 March 2011

Published: 30 March 2011

\section{References}

1. Adami $\mathrm{HO}$, Bergstrom $\mathrm{R}$, Hansen J: Age at first primary as a determinant of the incidence of bilateral breast cancer. Cumulative and relative risks in a population-based case-control study. Cancer 1985, 55(3):643-647.

2. Rutqvist LE, Cedermark B, Glas U, Mattsson A, Skoog L, Somell A, Theve T, Wilking N, Askergren J, Hjalmar ML, Rotstein S, Perveck L, Ringborg U: Contralateral primary tumors in breast cancer patients in a randomized trial of adjuvant tamoxifen therapy. Journal of the National Cancer Institute 1991, 83(18):1299-1306.

3. Alkner S, Bendahl PO, Ferno M, Nordenskjold B, Ryden L: Tamoxifen reduces the risk of contralateral breast cancer in premenopausal women: Results from a controlled randomised trial. Eur J Cancer 2009, 45(14):2496-2502.

4. Hartman M, Czene K, Reilly M, Adolfsson J, Bergh J, Adami HO, Dickman PW, Hall P: Incidence and prognosis of synchronous and metachronous bilateral breast cancer. J Clin Oncol 2007, 25(27):4210-4216.

5. Hartman M, Czene K, Reilly M, Bergh J, Lagiou P, Trichopoulos D, Adami HO, Hall P: Genetic implications of bilateral breast cancer: a population based cohort study. The lancet oncology 2005, 6(6):377-382.

6. Brommesson S, Jonsson G, Strand C, Grabau D, Malmstrom P, Ringner M, Ferno $M$, Hedenfalk I: Tiling array-CGH for the assessment of genomic similarities among synchronous unilateral and bilateral invasive breast cancer tumor pairs. BMC clinical pathology 2008, 8:6.

7. Imyanitov EN, Hanson KP: Molecular pathogenesis of bilateral breast cancer. Cancer letters 2003, 191(1):1-7.

8. Shibata A, Tsai YC, Press MF, Henderson BE, Jones PA, Ross RK: Clonal analysis of bilateral breast cancer. Clin Cancer Res 1996, 2(4):743-748.

9. Janschek E, Kandioler-Eckersberger D, Ludwig C, Kappel S, Wolf B, Taucher S, Rudas M, Gnant M, Jakesz R: Contralateral breast cancer: molecular differentiation between metastasis and second primary cancer. Breast Cancer Res Treat 2001, 67(1):1-8

10. Verkooijen HM, Chatelain V, Fioretta G, Vlastos G, Rapiti E, Sappino AP, Bouchardy C, Chappuis PO: Survival after bilateral breast cancer: results from a population-based study. Breast Cancer Res Treat 2007, 105(3):347-357.
11. Heron DE, Komarnicky LT, Hyslop T, Schwartz GF, Mansfield CM: Bilateral breast carcinoma: risk factors and outcomes for patients with synchronous and metachronous disease. Cancer 2000, 88(12):2739-2750.

12. Takahashi H, Watanabe K, Takahashi M, Taguchi K, Sasaki F, Todo S: The impact of bilateral breast cancer on the prognosis of breast cancer: a comparative study with unilateral breast cancer. Breast cancer (Tokyo, Japan) 2005, 12(3):196-202.

13. Dawson LA, Chow E, Goss PE: Evolving perspectives in contralateral breast cancer. Eur J Cancer 1998, 34(13):2000-2009.

14. Burns PE, Dabbs K, May C, Lees AW, Birkett LR, Jenkins HJ, Hanson J: Bilateral breast cancer in northern Alberta: risk factors and survival patterns. Canadian Medical Association journal 1984, 130(7):881-886.

15. Quan G, Pommier SJ, Pommier RF: Incidence and outcomes of contralateral breast cancers. American journal of surgery 2008, 195(5):645-650, discussion 650.

16. Kuo WH, Yen AM, Lee PH, Chen KM, Wang J, Chang KJ, Chen TH, Tsau HS: Cumulative survival in early-onset unilateral and bilateral breast cancer: an analysis of 1907 Taiwanese women. British journal of cancer 2009, 100(4):563-570.

17. Holmberg L, Adami HO, Ekbom A, Bergstrom R, Sandstrom A, Lindgren A: Prognosis in bilateral breast cancer. Effects of time interval between first and second primary tumours. British journal of cancer 1988, 58(2):191-194.

18. Carmichael AR, Bendall $S$, Lockerbie L, Prescott $R$, Bates $T$ : The long-term outcome of synchronous bilateral breast cancer is worse than metachronous or unilateral tumours. Eur J Surg Oncol 2002, 28(4):388-391.

19. Lu W, Schaapveld M, Jansen L, Bagherzadegan E, Sahinovic MM, Baas PC, Hanssen LM, van der Mijle HC, Brandenburg JD, Wiggers T, De Bock GH: The value of surveillance mammography of the contralateral breast in patients with a history of breast cancer. Eur J Cancer 2009, 45(17):3000-3007.

20. Rubino C, Arriagada R, Delaloge S, Le MG: Relation of risk of contralateral breast cancer to the interval since the first primary tumour. British journal of cancer 2010, 102(1):213-9.

21. Imyanitov EN, Suspitsin EN, Grigoriev MY, Togo AV, Kuligina E, Belogubova EV, Pozharisski KM, Turkevich EA, Rodriquez C, Cornelisse CJ, Hanson KP, Theillet C: Concordance of allelic imbalance profiles in synchronous and metachronous bilateral breast carcinomas. International journal of cancer 2002, 100(5):557-564.

22. Hemminki K, Granstrom C: Morphological types of breast cancer in family members and multiple primary tumours: is morphology genetically determined? Breast Cancer Res 2002, 4(4):R7.

23. Howell A, Cuzick J, Baum M, Buzdar A, Dowsett M, Forbes JF, HoctinBoes G, Houghton J, Locker GY, Tobias JS: Results of the ATAC (Arimidex, Tamoxifen, Alone or in Combination) trial after completion of 5 years' adjuvant treatment for breast cancer. Lancet 2005, 365(9453):60-62.

24. Fisher B, Dignam J, Bryant J, DeCillis A, Wickerham DL, Wolmark N, Costantino J, Redmond C, Fisher ER, Bowman DM, Deschênes L, Dimitrov NV, Margolese RG, Robidoux A, Shibata $H$, Terz J, Paterson AH, Feldman MI, Farrar W, Evans J, Lickley HL: Five versus more than five years of tamoxifen therapy for breast cancer patients with negative lymph nodes and estrogen receptor-positive tumors. Journal of the National Cancer Institute 1996, 88(21):1529-1542.

25. Systemic treatment of early breast cancer by hormonal cytotoxic or immune therapy. 133 randomised trials involving 31,000 recurrences and 24,000 deaths among 75,000 women. Early Breast Cancer Trialists' Collaborative Group. Lancet 1992, 339(8785):71-85.

26. Swain SM, Wilson JW, Mamounas EP, Bryant J, Wickerham DL, Fisher B, Paik S, Wolmark N: Estrogen receptor status of primary breast cancer is predictive of estrogen receptor status of contralateral breast cancer. Journal of the National Cancer Institute 2004, 96(7):516-523.

27. Arpino G, Weiss HL, Clark GM, Hilsenbeck SG, Osborne CK: Hormone receptor status of a contralateral breast cancer is independent of the receptor status of the first primary in patients not receiving adjuvant tamoxifen. J Clin Oncol 2005, 23(21):4687-4694.

28. Cuzick J, Powles T, Veronesi U, Forbes J, Edwards R, Ashley S, Boyle P: Overview of the main outcomes in breast-cancer prevention trials. Lancet 2003, 361(9354):296-300.

29. Impact of follow-up testing on survival and health-related quality of life in breast cancer patients. A multicenter randomized controlled trial. The GIVIO Investigators. JAMA 1994, 271(20):1587-1592. 
30. Rosselli Del Turco M, Palli D, Cariddi A, Ciatto S, Pacini P, Distante V: Intensive diagnostic follow-up after treatment of primary breast cancer. A randomized trial. National Research Council Project on Breast Cancer follow-up. JAMA 1994, 271(20):1593-1597.

31. Lu WL, Jansen L, Post WJ, Bonnema J, Van de Velde JC, De Bock GH: Impact on survival of early detection of isolated breast recurrences after the primary treatment for breast cancer: a meta-analysis. Breast Cancer Res Treat 2009, 114(3):403-412.

32. Houssami N, Ciatto S, Martinelli F, Bonardi R, Duffy SW: Early detection of second breast cancers improves prognosis in breast cancer survivors. Ann Oncol 2009, 20(9):1505-1510.

33. Jacobs HJ, van Dijck JA, de Kleijn EM, Kiemeney LA, Verbeek AL: Routine follow-up examinations in breast cancer patients have minimal impact on life expectancy: a simulation study. Ann Oncol 2001, 12(8):1107-1113.

34. Grunfeld E, Noorani H, McGahan L, Paszat L, Coyle D, van Walraven C, Joyce J, Sawka C: Surveillance mammography after treatment of primary breast cancer: a systematic review. Breast (Edinburgh, Scotland) 2002, 11(3):228-235.

35. de Bock GH, Bonnema J, van der Hage J, Kievit J, van de Velde CJ: Effectiveness of routine visits and routine tests in detecting isolated locoregional recurrences after treatment for early-stage invasive breast cancer: a meta-analysis and systematic review. J Clin Oncol 2004, 22(19):4010-4018.

36. Lawrence $G$, Wallis M, Allgood P, Nagtegaal ID, Warwick J, Cafferty FH, Houssami N, Kearins O, Tappenden N, O'Sullivan E, Duffy SW: Population estimates of survival in women with screen-detected and symptomatic breast cancer taking account of lead time and length bias. Breast Cancer Res Treat 2009, 116(1):179-185.

37. Duffy SW, Nagtegaal ID, Wallis M, Cafferty FH, Houssami N, Warwick J, Allgood PC, Kearins O, Tappenden N, O'Sullivan E, Lawrence G: Correcting for lead time and length bias in estimating the effect of screen detection on cancer survival. American journal of epidemiology 2008, 168(1):98-104.

38. Paci $E$, Coviello E, Miccinesi G, Puliti D, Cortesi L, De Lisi V, Ferretti S, Mangone L, Perlangeli V, Ponti A, Ravaioli A, de' Bianchi PS, Segnan N, Stracci F, Tumino R, Zarcone M, Zorzi M, Zappa M, IMPACT Working Group: Evaluation of service mammography screening impact in Italy. The contribution of hazard analysis. Eur J Cancer 2008, 44(6):858-865.

39. Dawson SJ, Duffy SW, Blows FM, Driver KE, Provenzano E, LeQuesne J, Greenberg DC, Pharoah P, Caldas C, Wishart GC: Molecular characteristics of screen-detected vs symptomatic breast cancers and their impact on survival. British journal of cancer 2009, 101(8):1338-1344.

40. Joensuu H, Lehtimaki T, Holli K, Elomaa L, Turpeenniemi-Hujanen T, Kataja V, Anttila A, Lundin M, Isola J, Lundin J: Risk for distant recurrence of breast cancer detected by mammography screening or other methods. Jama 2004, 292(9):1064-1073.

41. Shen $Y$, Yang $Y$, Inoue $L Y$, Munsell MF, Miller AB, Berry DA: Role of detection method in predicting breast cancer survival: analysis of randomized screening trials. Journal of the National Cancer Institute 2005, 97(16):1195-1203.

42. Wishart GC, Greenberg DC, Britton PD, Chou P, Brown CH, Purushotham AD, Duffy SW: Screen-detected vs symptomatic breast cancer: is improved survival due to stage migration alone? British journal of cancer 2008, 98(11):1741-1744.

Pre-publication history

The pre-publication history for this paper can be accessed here: http://www.biomedcentral.com/1471-2407/11/114/prepub

doi:10.1186/1471-2407-11-114

Cite this article as: Alkner et al:: Prediction of outcome after diagnosis

of metachronous contralateral breast cancer. BMC Cancer 2011 11:114.

\section{Submit your next manuscript to BioMed Central and take full advantage of:}

- Convenient online submission

- Thorough peer review

- No space constraints or color figure charges

- Immediate publication on acceptance

- Inclusion in PubMed, CAS, Scopus and Google Scholar

- Research which is freely available for redistribution 